\title{
Diabetes and extreme altitude mountaineering
}

Increasing numbers of people with diabetes are seeking advice about participation in high altitude climbing, which has the problems of serious metabolic demands, a high likelihood of acute mountain sickness (AMS), ${ }^{1}$ and leaving the climber remote from medical care. The American Diabetes Association states that "all levels of exercise, including leisure activities, recreational sports, and competitive professional performance, can be performed by people with type 1 diabetes who do not have complications and are in good blood glucose control". ${ }^{2}$ But, are all forms of sport suitable for people with type 1 diabetes? Lack of data on the effects of altitude on blood glucose control has led to reticence among members of the medical profession to endorse high altitude mountaineering for people with diabetes

The Diabetes Federation of Ireland Expedition to Kilimanjaro $(4559 \mathrm{~m})$ gave some indication of the potential hazards of extreme altitude for diabetic climbers. ${ }^{3}$ Symptoms of AMS, as measured by the well validated Lake Louise scoring system, ${ }^{4}$ occurred with similar frequency in diabetic and non-diabetic climbers, indicating that diabetes per se does not predispose to the development of altitude sickness. Severe complications of altitude, such as high altitude pulmonary oedema and high altitude cerebral oedema, occurred exclusively in the non-diabetic group, and retinal haemorrhages, which have been reported to occur in one third of climbers above $5000 \mathrm{~m}$, occurred in two diabetic (one of whom had pre-existing retinopathy) and three non-diabetic climbers. Six of 16 people with diabetes and 16 of 22 non-diabetic climbers reached the summit of the mountain, although the mean altitude attained was lower in the diabetic group.

Despite the fact that complications of altitude did not occur with greater frequency in the diabetic climbers, a number of this group experienced serious difficulties. Some of the symptoms of altitude sickness, such as headache and light-headedness, made the recognition of hypoglycaemia more difficult, as did the paraesthesia associated with the use of acetazolamide to prevent AMS. In the absence of reliable warning signs for hypoglycaemia therefore patients were more reliant on the results of blood glucose testing. In common with other studies, however, ${ }^{6-8}$ at altitudes above $3700 \mathrm{~m}$, blood glucose meters gave readings that were $60-80 \%$ of standard glucose solutions, particularly when ambient temperature was low. ${ }^{3}$ On the night of the summit attempt, when temperatures fell to $-22^{\circ} \mathrm{C}$, some meters completely ceased to function. This made accurate glycaemic control impossible.

Furthermore, a number of factors combined to increase the risk of ketoacidosis. When anorexia secondary to AMS occurred, climbers tended to compensate for poor carbohydrate intake by reducing insulin, to prevent hypoglycaemia during exercise. Four climbers who reduced insulin in this fashion developed ketosis and mild hyperglycaemia, and two of these developed more serious AMS close to the summit. With the onset of nausea and vomiting, both climbers developed hyperglycaemia and ketonuria, a progression that was accelerated by the tendency to dehydration at high altitude if fluid intake is inadequate. At high altitude, both climbers were obliged to descend for several thousand feet before they could be evacuated from the mountain, and the additional exercise exacerbated the generation of ketones and the development of ketoacidosis. Treatment with intravenous saline and intramuscular insulin was begun at $4000 \mathrm{~m}$, before evacuation by stretcher, whereupon one climber recovered quickly. The other climber required hospital admission, and, despite rapid normalisation of blood glucose concentrations and clearing of ketonuria, acidosis persisted for several days. As prophylaxis against AMS, this climber had been taking acetazolamide, which blocks bicarbonate reabsorption in the renal tubules and has been reported to induce metabolic acidosis; acetazolamide may have contributed to the persistent acidosis in this patient.

So what advice should be given to a person with type 1 diabetes contemplating high altitude mountaineering? The experience of the six climbers who reached the summit of Kilimanjaro suggests that people with diabetes are able to participate in this demanding and potentially dangerous sport. However, high altitude mountaineering presents significant hazards for those with diabetes. The possibility of retinal haemorrhage should caution against those with significant retinopathy from ascending to high altitude. Recognition of hypoglycaemia, which occurs more commonly during hillwalking than in other sports, ${ }^{9}$ is difficult because of the symptoms of AMS and the inaccuracy of blood glucose meters. In addition, once symptoms of AMS occur, particularly vomiting, there is a significant likelihood of diabetic ketoacidosis, which is a serious complication, shown in one study of trekkers to account for $8 \%$ of deaths at high altitude. ${ }^{10}$ Acetazolamide, which has recently been reported to be useful in preventing AMS only at high doses of $750 \mathrm{mg}$ a day, ${ }^{11}$ may also predispose towards ketoacidosis in diabetic climbers. Once things go wrong, climbers may have to walk long distances from remote mountains before they can be evacuated to medical care, which may worsen developing ketoacidosis.

Patients will make their own decision about participation in high altitude mountaineering, but should do so with the benefit of informed advice about the potential hazards. For patients with type 1 diabetes, the dangers of developing ketoacidosis, with potentially fatal outcome, are considerable. The key risk factor for the development of ketoacidosis seems to be the development of AMS, so any measures taken to reduce the risk of AMS - the most important of which is gradual ascent to allow acclimatisation-should be encouraged.

K MOORE C THOMPSON

Department of Diabetes, Beaumont Hospital, Dublin, Ireland chris.thompson@beaumont.ie

Department of Medicine, City Hospital, Belfast, Ireland

R HAYES

1 Diabetes mellitus and exercise. American Diabetes Association Position Statement. Diabetes Care 1997;20:1908-12

2 Maggirini M, Buhler B, Walter M, et al. Prevalence of acute mountain sickness in the Swiss Alps. BMF 1990;301:853-5.

3 Moore K, Vizzard N, Coleman C, et al. Extreme altitude mountaineering and Type 1 diabetes mellitus; the Diabetes Federation of Ireland Kilimanjaro Expedition. Diabet Med 2001 (in press).

4 Roach RC, Bartsch P, Hackett PH, et al. The Lake Louise acute mountain sickness scoring system. In: Sutton JR, Houston CS, Coates G, eds. Hypoxia and molecular medicine. 1st ed. Burlington (VT): Queen City Printers, 1993:52-9.

5 Hackett PH, Rennie D. Rales, peripheral edema, retinal haemorrhage and acute mountain sickness. Am f Med 1979;67:214-18.

6 Giordano N, Trash W, Hollenbaugh L, et al. Performance of seven blood glucose testing systems at high altitude. Diabetes Educ 1989:15;444-8.

7 Plucose testing systems at high altitude. Diabetes Educ 1989:15;444-8. $3,000 \mathrm{~m}$ on performance of glucose meters. Diabetes Care 2000:23;129-31. Gautier JF, Bigard AX, Douce P, et al. Influence of simulated altitude on the performance of five blood glucose meters. Diabetes Care 1996:19;1430-33. 9 Thompson CJ, Connacher A, Rewt D, et al. Exercise in children and adolescents. In: Exercise and sport in diabetes Burr B, Nagi D, eds. Chichester: John Wiley \& Son 1999, 83-96.

10 Schlim DR, Gallie, J. The causes of death amongst trekkers in Nepal. Int $\mathcal{F}$ Sports Med 1992;13:74-6.

11 Dumont L, Mardirosoff C, Tramer, MR. Efficacy and harm of pharmacological prevention of acute mountain sickness: quantitative systematic review. $B M \mathcal{F}$ 2000;321:267-72. 